\title{
Factors associated with health-related quality of life among hemodialysis patients in the DOPPS
}

\author{
Antonio Alberto Lopes · Jennifer L. Bragg-Gresham - David A. Goodkin • \\ Shunichi Fukuhara · Donna L. Mapes · Eric W. Young · Brenda W. Gillespie · \\ Tadao Akizawa - Roger N. Greenwood - Vittorio E. Andreucci - Takashi Akiba • \\ Philip J. Held · Friedrich K. Port
}

Published online: 4 May 2007

(C) Springer Science+Business Media B.V. 2007

\section{Erratum to: Qual Life Res (2007) 16:545-557 \\ DOI 10.1007/s11136-006-9143-7}

There was an error in the Appendix of the original article. The 'Questions or Items' text for 'Role emotional' was incorrect. The correct text is shown in the column on the right.

\begin{tabular}{ll}
\hline Scale & Questions or Items \\
\hline Role emotional & During the past 4 weeks, have you had any of the \\
& following problems with your work or other \\
& regular activities as a result of any emotional \\
& problems (such as feeling depressed or \\
& anxious)? Cut down on the amount of time you \\
& spent on work or other acitivities; \\
& $\begin{array}{l}\text { Accomplished less than you would like; Didn't } \\
\text { do work or other activities as carefully as } \\
\text { usual. Possible responses: yes or no. }\end{array}$
\end{tabular}

E. W. Young

Division of Nephrology, University of Michigan and

VAMC, Ann Arbor, MI, USA

T. Akizawa

Wakayama Medical University, Wakayama, Japan

R. N. Greenwood

Lister Hospital, Stevenage, UK

V. E. Andreucci

Università Federico II, Naples, Italy

T. Akiba

Tokyo Women's Medical University, Tokyo, Japan

\section{A. Goodkin}

ICOS Corporation, Bothell, WA, USA

S. Fukuhara

Graduate School of Medicine and Public Health, Kyoto

University, Kyoto, Japan 